\title{
DIGITAL MARKETING SEBAGAI METODA ALTERNATIF WIRAUSAHA BAGI MAHASISWA DI UNIVERSITAS NEGERI PADANG
}

\author{
Muhamad Adri $^{1}$, Hanesman ${ }^{2}$, Titi Sriwahyuni ${ }^{3}$, Almasri $^{4}$ \\ ${ }^{1,3}$ Pendidikan Teknik Informatika, Fakultas Teknik, UNP \\ ${ }^{2,4}$ Pendidikan Teknik Elektronika, Fakultas Teknik, UNP \\ E-mail: mhd.Adri@unp.ac.id
}

\begin{abstract}
Digital technology and the internet have opened opportunities for people to develop social interaction through this technology, with the birth of web technology, media and social networks, which led to the industrial revolution 4.0. This technology presents a new trend in building a business called Digital Marketing (DM). DM provides new opportunities for anyone to do entrepreneurship without being limited by time, place and region. Universitas Negeri Padang (UNP) answers the entrepreneurship education policy by making Entrepreneurship as a compulsory subject, promoting entrepreneurial student programs and integrated service units for career guidance and entrepreneurship. This paper examines how DM can be used as an alternative method of entrepreneurship for UNP students, which has touching student life as a millennial generation. The experimental method is used to see of improvement the knowledge and skills of students in DM through DM Learning and Development of DM eLearning Resources (DMLR). The instruments before and after learning were developed to measure of program achieving, to assess the results of the DMLR development. The results of this study showed an increase in student knowledge and skills in DM with significant value 70-85\% and a good assessment of the developed DMLR with very satisfied score category.
\end{abstract}

Keyword: 4.0 Industrial Revolution, Internet Technology, Social Media, Social Networking, Digital Marketing, eLearning Resources

\section{PENDAHULUAN}

Kehadiran revolusi Industri 4.0, menjadikan teknologi digital dan internet sebagai tulang punggung teknologi [1], telah mengubah paradigma masyarakat dalam berbagai sektor kehidupan, termasuk dunia pendidikan, yang melahirkan pendidikan di era Revolusi 4.0 yang disebut sebagai Pendidikan 4.0 dengan automatisasi yang berpusat pada sistem jaringan internet dan digitalisasi media baik dalam proses pra pembelajaran maupun pasca pembelajaran [2], yang terhubung melalui electronic devices yang memiliki kemampuan untuk memproses, menyimpan, dan mengakses pengetahuan untuk pembelajaran melalui internet baik dari komputer, tablet, atau smartphone.

Selanjutnya, fenomena Pendidikan 4.0 juga telah menciptakan generasi manusia baru yang disebut generasi Z. Generasi Z yang lahir dan dibesarkan di era digital adalah pengguna teknologi yang melek, cerdas, dan fasih, yang disebut sebagai digital natives [3], yang kesehariannya tidak lepas dari penggunaan gadget yang terkoneksi internet dalam berinteraksi sosial di dunia maya. Setiap hari, menggunakan perangkat mobile gadget untuk akses informasi, tidak membedakan dunia offline dan online, bahkan saat mereka berada di lingkungan belajar sekalipun mereka tetap online [4]. Di satu sisi gadget dapat mengganggu proses pembelajaran, akan tetapi di sisi lain penggunaan gadget dapat memberikan kemudahan belajar baik bagi pendidik maupun peserta didik [5]. Jika kita menelisik sisi positif dari penomena ini, maka kita bisa memutarbalikkannya menjadi suatu kesempatan emas untuk membuat gebrakan bagi kemudahan pengajaran dan pembelajaran digital tanpa mendeskridit ataupun melawan perkembangan disrupsi teknologi [6] yang ada baik di institusi formal, non-formal, maupun informal, dengan mengubah entertained netizen menjadi educated netizen. Inovasi ini diharapkan dapat 
membantu para pendidik untuk mempersiapkan anak didiknya menghadapi zaman milenial sehingga 5C sebagai kompetensi dasar yang dibutuhkan anak didik zaman now yang meliputi: creative, critical thinking, collaboration, communication, dan confidence [7] dapat terakomodir, demi meningkatkan daya saing peserta didik di tengah persaingan global.

Kurun waktu 10 tahun belakangan pendidikan kewirausahaan (entrepreneurship) di Indonesia menjadi trend. Sampai detik ini semangat kewirausahaan di perguruan tinggi bahkan sekolah menengah dan dasar di Indonesia terus tumbuh dan berkembang melalui penyelenggaraan pendidikan kewirausahaan. Apa yang menyebabkan semangat kewirausahaan di Indonesia begitu menggelora? Jawabannya sederhana, karena Indonesia saat ini butuh perjuangan yang lebih serius dalam mengejar ketertinggalan dari negara-negara lain dalam kemajuan perekonomian. Bahkan yang menjadi permasalahan adalah kemajuan ekonomi negaranegara tersebut antara lain ditentukan oleh jumlah pengusahanya [8].

Kesadaran akan pentingnya Pendidikan kewirausahaan didorong oleh pernyataan Sosiolog David Mc.Clelland dalam [9] bahwa sedikitnya dibutuhkan minimal $2 \%$ wirausaha dari populasi penduduknya agar suatu negara dapat menjadi negara yang maju. Pernyataan ini tentu sangat beralasan karena di beberapa negara maju di dunia jumlah pengusaha melebihi 2 persen. Data menunjukkan Amerika Serikat memiliki 12,5 persen jumlah pengusaha dari total penduduknya. Beberapa negara maju lainnya seperti Jepang 10 persen, Inggris 10 persen, Singapura 7,5 persen. Bahkan negara berkembang seperti China 2,5 persen, India 2,5 persen dan Malaysia 2,5 persen. Sedangkan bila dibandingkan dengan Indonesia yang saat ini baru memiliki 0,2 persen jumlah pengusaha dari total penduduk yang mencapai 237 juta jiwa [10]. Untuk memenuhi jumlah pengusaha sekitar 4,8 juta orang ( 2 persen), salah satu upaya yang dapat ditempuh adalah melalui pendidikan kewirausahaan di perguruan tinggi sebagai gerbang yang diharapkan dapat menghasilkan wirausaha baru.

Mata kuliah kewirausahaan saat ini menjadi mata kuliah wajib di semua perguruan tinggi. Hal ini merupakan tindak lanjut dari rencana pemerintah dalam rangka menggalakkan potensi kewirausahaan di masyarakat guna menciptakan lapangan pekerjaan sekaligus mengurangi angka pengangguran yang selama ini masih terus menjadi momok bagi masyarakat. Kewirausahaan selain dapat dipelajari, juga harus dapat diinternalisasi secara luas melalui proses pendidikan. Individu yang memiliki jiwa Kewirausahaan adalah individu yang mengenal potensi dirinya dengan baik, belajar mengembangkan potensi untuk melihat dan mengkreasikan peluang dalam mewujudkan citacitanya.

Oleh karena itu Pendidikan Tinggi sebagai pusat pengembangan ilmu pengetahuan dan teknologi berperan dalam mempersiapkan pemimpin di era industri 4.0 [11]. Mahasiswa sebagai calon pemimpin di era industry 4.0 fokus pada literasi data, teknologi, dan kemanusiaan [12]. Untuk menjadikan generasi yang kreatif, inovatif dan adaptif terhadap kehadiran teknologi.

Universitas Negeri Padang (UNP), sebagai salah satu Perguruan Tinggi Negeri (PTN) terkemuka di Sumatera Barat, telah mengambil perang penting dalam menciptakan programprogram kewirausahaan, dengan berbagai wujud dan langkah yang real. Pada level kebijakan strategis, pengembangan program kewirausahaan ini tertuang dalam Rencana Strategis UNP 20152019, yang menjadikan keterlibatan mahasiswa dalam program kewirausahaan sebagai salah satu Program Prioritas Pengembangan UNP [13:54]. Realisasi Renstra ini dengan menjadikan Mata Kuliah Kewirausahaan sebagai Mata Kuliah Wajib bagi seluruh mahasiswa UNP, juga berbagai program hibah ditawarkan kepada mahasiswa, seperti Program Mahasiswa Wirausaha (PMW). Disamping itu, untuk lebih mempertegas program kewirausahaan ini, maka didirikanlah lembaga setingkat Unit Pelaksana Teknik (UPT) dengan fokus layanan pada bidang Kewirausahaan yang disebut dengan UPT. Pengembangan Karir dan Kewirausahaan (UPT. PKK).

Program kewirausahaan ini sejauh ini berjalan dengan baik di UNP Padang. Dalam Laporan Kinerja UNP Tahun 2018 [14:33], terdapat kecendrungan ketercapaian program kewirausahaan mahasiswa realisasinya melampaui target yang ditetapkan, seperti terlihat pada Gambar 1.

Pada Gambar 1 ini dapat dilihat bahwa pada terdapat kecendrungan hasil yang dicapai melebihi target, seperti pada Tahun 2017, ditargetkan 150 mahasiswa yang berwirausaha, hasil yang diperoleh adalah 304 mahasiswa, dengan target pencapaian $203 \%$.

Demikian juga dengan Tahun 2018 kemaren, dari 250 mahasiswa yang ditargetkan, tercapai 261 mahasiswa, dengan peningkatan 104\%. Meskipun persentase dan jumlah target capaian 2018 jauh menurun dari 2017, namun ini dapat dijadikan sebagai dasar dalam menetapkan program-program pendukung di luar dari program 
yang telah ada di dalam Rencana Kerja UNP 2018 untuk disempurnakan pada tahun 2019 ini.

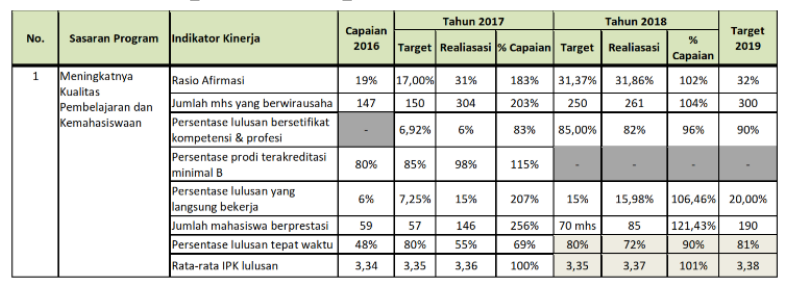

Gambar 1. Target dan capaian Indikator Kinerja UNP 2018

Demikian juga dengan Tahun 2018 kemaren, dari 250 mahasiswa yang ditargetkan, tercapai 261 mahasiswa, dengan peningkatan 104\%. Meskipun persentase dan jumlah target capaian 2018 jauh menurun dari 2017, namun ini dapat dijadikan sebagai dasar dalam menetapkan program-program pendukung di luar dari program yang telah ada di dalam Rencana Kerja UNP 2018 untuk disempurnakan pada tahun 2019 ini.

Tentu saja data tersebut menjadi pertanyaan mengapa terjadi penurunan minat mahasiswa? Apakah dikarenakan oleh masih terlalu kakunya pola pembelajaran kewirausahaan yang terjadi di kelas? Atau tekanan pertanggungjawaban program kewirausahaan mahasiswa yang terlalu tinggi, sehingga terjadi penurunan antusias mahasiswa dalam berwirausaha, atau mahasiswa masih merasa bahwa bekal yang di dapatkan belum mencukupi bagi mereka untuk menjadi seorang wirausahawan.

Kurikulum Kewirausahaan yang dikembangkan sebagai Mata Kuliah Umum tingkat Universitas, telah disusun secara cermat dengan penyesuaian pada beberapa aspek, baik aspek teoritis dan landasan konseptual, aspek pengalaman mahasiswa dalam membangun sebuah usaha baru, maupun aspek teknologi pada era R4.0 ini, sebagaimana tertuang di dalam Rencana Pembelajaran Semester (RPS) Kewirausahaan [15], seperti : a) Pengantar Kewirausahaan, peran wirausaha dalam pembangunan bangsa, faktorfaktor penyebab keberhasilan wirausahawan dan motivasi kewirausahaan b) Definisi kewirausahaan, syarat-syarat dan sifat-sifat wirausaha, c) langkahlangkah dalam memulai usaha, d) ide dan gagasan usaha serta mengalisis jenis usaha, e) Menyusun dan merencanakan Perencanaan Bisnis, f) mengembangkan peluang usaha dengan dukungan teknologi informasi, g) Praktik Perencanaan bisnis, dan h) Praktik Kewirausahaan selama 4 minggu.

Jika dilihat dari kurikulum Kewirausahaan yang ditawarkan, secara konsep dan cara berpikir, diharapkan telah mampu mengubah mindset mahasiswa dan membangun jiwa wirausaha.
Namun terbatasnya waktu untuk praktik dalam menjalankan usahanya, serta padatnya kandungan teoritis dan kegiatan perkuliahan menjadi faktor yang disinyalir tidak bertahan lamanya semangat berwirausaha pada mahasiswa, hal ini diperoleh dari hasil survei awal yang dilakukan kepada 180 orang mahasiswa yang berasal dari 4 kelas Kewirausahaan pada Semester Juli - Desember 2018 dan Semester Januari - Juni 2019. Berdasarkan hasil survey tersebut, mahasiswa kerap kali dihadapkan pada persoalan modal awal usaha yang masih sangat rendah, sehingga usaha yang dirintis oleh mahasiswa adalah usaha-usaha dengan modal yang sekecil mungkin dari iuran anggota group usahanya yang terdiri dari 3-4 orang mahasiswa, sehingga praktik wirausaha yang dilakukan hanya baru mampu pengalaman dalam melakukan teknik "selling product", baik untuk produk-produk jadi sebagai "reseller", maupun produk-produk hasil produksi sendiri, khususnya produk makanan ringan dan camilan, yang secara "de-facto" memiliki kompetitor dari pedagang sejenis di luar kampus, dan produk mereka sangat mudah untuk ditiru seketika oleh para kompetitor tersebut, meskipun dari sisi inovasi produk yang dilakukan mahasiswa masih jauh lebih unggul dibandingkan kompetitornya. Namun karena kompetitor adalah pedagang tetap, mereka memiliki waktu pemasaran yang lebih lama dibandingkan mahasiswa.

Untuk menjawab kendala modal usaha yang kecil tersebut, maka UNP menawarkan hibah Program Mahasiswa Wirausaha (PMW), dengan penyediaan dana sebesar Rp. 5.000.000,- pada tahun 2018 yang lalu dan sebesar Rp. 5.000.000,- Rp. 10.000.000,- pada tahun 2019 ini per-Proposal kelompok usaha mahasiswa, untuk merangsang dan menggerakkan semangat wirausaha mahasiswa, agar mahasiswa berlomba-lomba untuk menjadikan kampus untuk mencari pengalaman melalui kegiatan kewirausahaan agar kelak bisa menjadi entrepreneur.

Sedangkan dari aspek pemasaran, karena alokasi waktu dan tempat yang terbatas dimiliki oleh mahasiswa, maka sebagian besar mahasiswa melakukan pemasaran di dalam lingkungan kampus yang konsumennya adalah para mahasiswa, dosen dan pegawai UNP, yang disesuaikan dengan beban Praktik wirausaha yang diberikan dalam Mata Kuliah Kewirausahaan.

UNP sebagai instutusi pendidikan berupaya membekali mahasiswanya dengan berbagai program antara lain mendirikan unit kegiatan kampus wirausaha, mengikuti programprogram kewirausahaan yang diadakan oleh kemenristekdikti, sampai memasukkan mata kuliah 
wajib kewirausahaan di semua jenjang pendidikan. Sebagian besar mahasiswa UNP saat ini mulai sadar betapa pentingnya wirausaha sebagai salah satu solusi untuk mengatasi pengangguran setelah mereka menyelesaikan studi. Gambar 2 menunjukkan target dan capaian jumlah mahasiswa UNP yang mengikuti kegiatan kewirausahaan tahun 2018 [14: 35].

Gambar 2 memperlihatkan bahwa pada Tahun 2018 realisasi jumlah mahasiswa yang bewirausaha 261 orang mahasiswa dari Hasil Seleksi Program Mahasiswa Wirausaha (PMW) tahun 2018, dari yang ditargetkan yaitu 250 orang. Realisasi ini melampaui target sebesar 104\%.

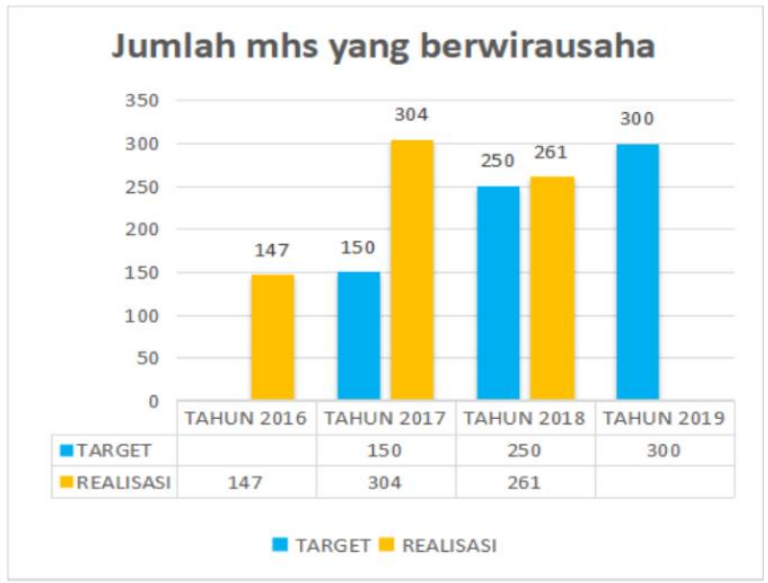

Gambar 2. Grafik Jumlah Mahasiswa yang berwirausaha di UNP

Terlampauinya target ini karena adanya sosialisasi kewirausahaan yang dilakukan diawal tahun kepada mahasiswa ke seluruh fakultas dan kuliah umum kewirausahaan dengan mendatangkan pengusaha-pengusaha sukses. Tahun 2017 Jumlah mahasiswa yang berwirausaha sejumlah 304 orang, angka ini lebih besar dibandingkan dengan tahun 2018. Hal ini karena masing-masing kelompok wirausaha tahun 2017 terdiri dari 5-7 orang, sementara tahun 2018 pengelompokannya sebanyak 4-5 orang. Tahun 2019 ditargetkan 300 orang mahasiswa yang lolos seleksi proposal kewirausahaan. Pencapaian target ini akan dilakukan dengan program pembinaan kepada mahasiswa dalam pembuatan proposal kegiatan kewirausahaan dan pelatihan kewirausahaan.

Memberikan pelatihan wirausaha ini menjadi tanggung jawab dan salah satu program utama dari UPT. PKK UNP sebagai salah unit yang diberi tanggung jawab dalam mengembangkan program-program kewirausahaan bagi mahasiswa di UNP, namun program Pelatihan yang diberikan masih terbatas pada tataran Perencanaan Bisnis, dan masih jauh dari langkah Best-Practice bagi mahasiswa dalam berwirausaha, sebagai jawaban atas kendala yang dihadapi oleh mahasiswa saat ini, agar usaha yang telah dirintis dalam perkuliahan tidak hanya sekedar menjadi "bisnis pra-syarat lulus" mata kuliah Kewirausahaan.

Kehadiran teknologi saat ini, sesungguhnya merupakan peluang sekaligus tantangan bagi mahasiswa dalam mengembangkan usaha yang telah dirintis saat kuliah tersebut. Menjadi peluang, karena dengan teknologi yang sudah menjadi "pakaian hidup" sehari-hari mahasiswa, dengan gadget yang dimiliki akan bisa menjadi mesin pemasaran dan produksi yang ampuh dalam menggapai pangsa pasar dan konsumen yang lebih luas. Menjadi tantangan, jika mahasiswa tidak dapat memanfaatkan teknologi secara tepat bagi pengembangan usahanya, maka akan datang kompetitor konvensional masuk ke ranah konsumen mereka dengan layanan teknologi, seperti kehadiran GoJek dengan Produk Go-Food, Go-Send maupun Grab dengan Grab-Food, dan penetrasi merchant-merchant melalui MarketPlace profesional seperti TokoPedia, BukaLapak dan lain-lain [16].

Oleh karena itu perlu upaya dukungan dari UPT. PKK dan UNP dalam membina mahasiswa sebagai usahawan baru dalam menghadapi penetrasi teknologi dalam wirausaha, seperti peningkatan fungsi gadget dan teknologi melalui konsep Digital Marketing dan best-practice-nya bagi mahasiswa dalam format digital bagi mahasiswa usahawan baru dalam memasarkan produk-produk usaha mereka, yang mungkin saja karena budaya malu menyebabkan mereka enggan untuk memasarkannya ke pangsa pasar yang lebih luar di luar kampus.

\section{PENDEKATAN PEMECAHAN MASALAH \\ Metode}

Penelitian ini menggunakan Metode Riset dan Pengembangan dengan model instruksional ADDIE [17] sebagai kerangka pengembangan, yang terdiri dari 5 tahapan prose pengembangan yaitu Analysis, Design, Development, Implementation dan Evaluation.

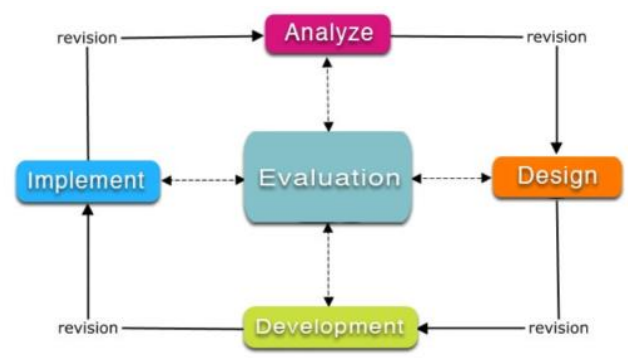


Gambar 3. Model Instruksional ADDIE yang dimodifikasi [18]

Tahapan masing-masing proses pada model ADDIE diimplementasikan dengan langkah sebagai berikut :

\section{Analysis}

Pada tahapan ini dilakukan analisis kesiapan dari mahasiswa UNP yang akan memggunakan Digital Marketing sebagai alternative wirausaha, baik dari sisi teknologi maupun minat dalam DM. Untuk kebutuhan analisis ini digunakan Digital Skill Framework [19]

\section{Design}

Pada tahapan ini dilakukan perancangan DMLR LMS dengan mengacu kepada Kurikulum Digital Marketing Profesional [20][21][22].

\section{Development}

Pada tahapan ini dilakukan pengembangan DMLR berbasis LMS dengan menggunakan LMS Open Source Moodle [23], [24],[25]

\section{Implementation}

Implementasi dilakukan dengan mengimplementasika struktur kurikulum DMLR ke LMS Moodle.

\section{Evaluation}

Evaluasi dilakukan untuk mengukur sejauh mana keberhasilan pengembangan DMLR berbasis LMS bagi pengembangan pengetahuan dan keterampilan DM Mahasiswa.

Untuk melihat sejauhmana DM menjadi metoda Alternatif berwirausaha bagi mahasiswa, maka digunakan langkah proses berikut ini :

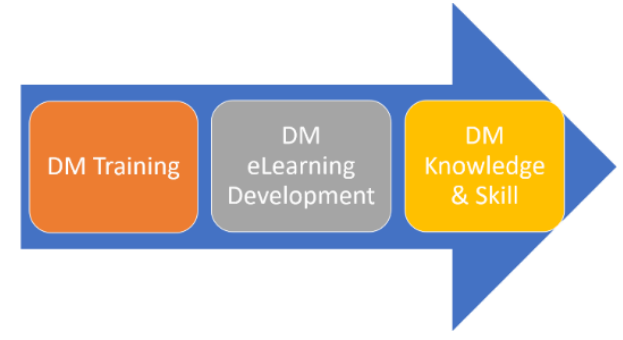

Gambar 4. Langkah Proses Penelitian

Langkah penelitian ini seperti terlihat pada Gambar 4, diawali dengan memberikan pelaitian DM kepada mahasiswa, kemudian untuk keberlanjutan belajar mandiri mahasiswa dalam DM, dikembangkan DMLR, sehingga dapat dijadikan sebagai rujukan dalam melakukan "reengineering knowledge" oleh mahasiswa.

\section{HASIL DAN PEMBAHASAN}

Pembelajaran dan Pembinaan DM

Pembelajaran dan Pembinaan DM

dilaksanakan sebagai pengetahuan dan keterampilan awal bagi mahasiswa wirausaha dalam merencanakan dan mengembangkan bisnis berbasis DM. Pembelajaran dan Pembinaan diberikan berdasarkan kepada Kurikulum DM Profesional, dengan sturktur seperti terlihat pad Tabel 1, dengan jumlah jam pembelajaran 48 jam.

Tabel 1. Materi Pembelajaran dan Pembinaan DM

\begin{tabular}{|c|c|}
\hline Materi & Jam \\
\hline $\begin{array}{l}\text { Kewirausahaan di Era Revolusi } 4.0 \text { : Peluang } \\
\text { dan Tantangan bagi Perguruan Tinggi }\end{array}$ & 4 \\
\hline Konsep Dasar Digital Marketing & 2 \\
\hline Rencana Bisnis berbasis Digital Marketing & 4 \\
\hline $\begin{array}{l}\text { Pemanfaatan Aplikasi Internet dan Digital } \\
\text { dalam Marketing }\end{array}$ & 4 \\
\hline Search Engine Markeiting & 4 \\
\hline Google Service, Tren \& Adsense & 4 \\
\hline Teknologi Web dan Digital Marketing & 4 \\
\hline Google Business untuk Digital Marketing & 3 \\
\hline $\begin{array}{l}\text { Social Network Marketing : Facebook, } \\
\text { Instagram, Whatsapp }\end{array}$ & 3 \\
\hline $\begin{array}{l}\text { Media Networking Marketing : Youtube } \\
\text { Marketing, Product Review \& Viewer } \\
\text { Penetration }\end{array}$ & 4 \\
\hline $\begin{array}{l}\text { MarketPlace Marketing : TokoPedia, } \\
\text { BukaLapak, OLX Marketing }\end{array}$ & 4 \\
\hline Praktikum Digital Marketing & 8 \\
\hline ah & 48 \\
\hline
\end{tabular}
berdasarkan kuesioner yang didistribusikan kepada mahasiswa DM, maka diperoleh hasil :

Tabel 2. Respon Kepuasan Mahasiswa DM

\begin{tabular}{lllll}
\hline Aspek Belajar DM & SP & PS & SD & KC \\
\hline Materi \& Kurikulum & 18 & 7 & 3 & 2 \\
Instruktur & 20 & 8 & 2 & 0 \\
Fasilitas Labor & 28 & 2 & 0 & 0 \\
Modul Latihan & 20 & 6 & 2 & 2 \\
Tim Panitia & 23 & 5 & 1 & 1 \\
Konsumsi & 15 & 5 & 3 & 7
\end{tabular}

$\mathrm{SP}=$ Sangat Puas, $\mathrm{PS}=$ Puas, $\mathrm{SD}=$ Sedang,

$\mathrm{KC}=$ Kecewa

\section{Pengembangan DMLR berbasis LMS dengan Model Instruksional ADDIE}

1. Hasil Analisis

Analisis kesiapan mahasiswa dalam mengimplementasikan DMLR, menggunakan Framework Digital Skill 


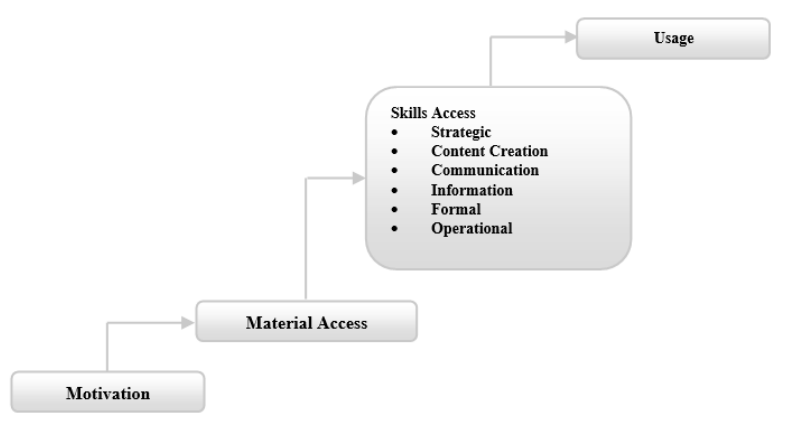

Gambar 5. Framework Digital Skill [19]

Berdasarkan framework tersebut di atas, maka kemudian dikembangkan instrument yang digunakan untuk melihat aspek motivasi, material akses, skill akses dan penggunaan teknologi digital oleh mahasiswa peserta DM.

Untuk kebutuhan analisis ini, maka dilakukan pemetaan kompetensi dasar teknologi digital mahasiswa, yang diukur dengan Pre and Post Learning Questionnaire design. Sebelum pelatihan kuesioner didistribusikan secara online kepada perwakilan 30 orang mahasiswa. Setelah survey awal, dan diperoleh hasil seperti pada Tabel 3.

Tabel 3. Data kompetensi awal TIK Mahasiswa Peserta DM

\begin{tabular}{lllll}
\hline Kompetensi TIK Dasar & PM & MN & MH & JML \\
\hline Pengoperasian Komputer & 10 & 12 & 8 & 30 \\
Aplikasi Office & 12 & 14 & 4 & 30 \\
Aplikasi Desain Grafis & 18 & 8 & 4 & 30 \\
Aplikasi Video Editing & 20 & 6 & 2 & 30 \\
Akses Internet & 12 & 14 & 4 & 30 \\
Internet Resources & 15 & 10 & 5 & 30 \\
Social Network \& Media & 20 & 8 & 2 & 30 \\
Business on Digital & 22 & 7 & 3 & 30 \\
Technology & & & & \\
\hline
\end{tabular}

$\mathrm{PM}=$ Pemula, $\mathrm{MN}=$ Menengah, $\mathrm{MH}=$ Mahir

Dari Tabel 3 dapat dilihat, mayoritas peserta memiliki kompetensi TIK Pemula dan Menengah pada beberapa aspek keterampilan TIK.

\section{Hasil Perancangan}

Rancangan DMLR berbasis LMS, dibangun berdsarkan kurikulum DM yang telah dijadikan rujukan, dengan peta konsep:

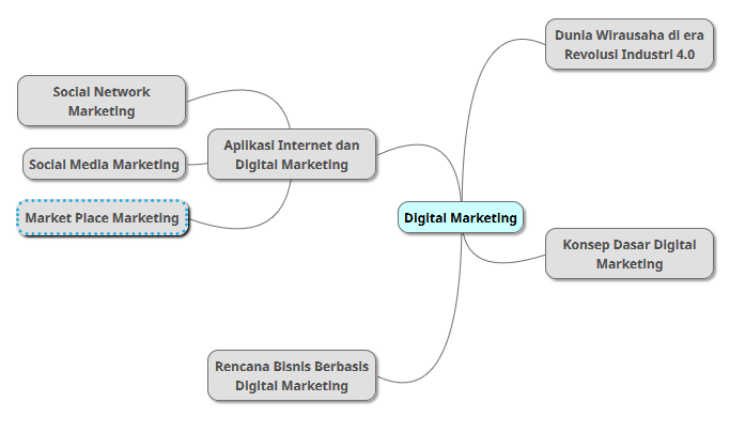

Gambar 6. Desain Peta Konsep Digital Marketing

3. Hasil Pengembangan

Berdsarkan hasil perancangan, maka kemudian dikembangkan DMLR berbasis LMS Moodle di instalasi dan dikonfigurasi sesuai dengan kebutuhan DMLR :

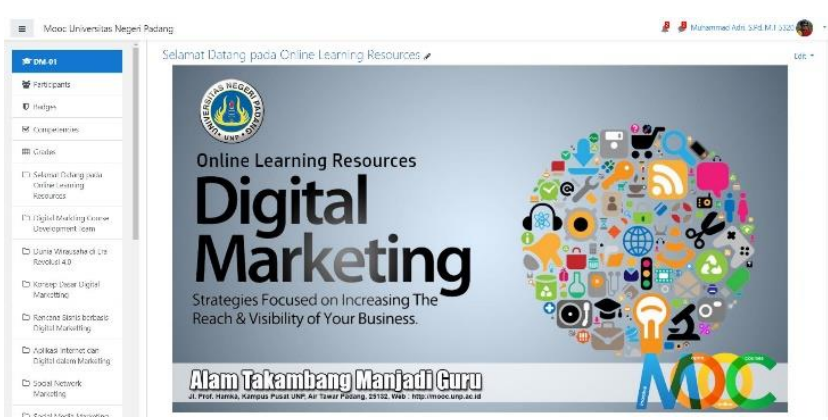

Gambar 7. Halaman Utama DMLR

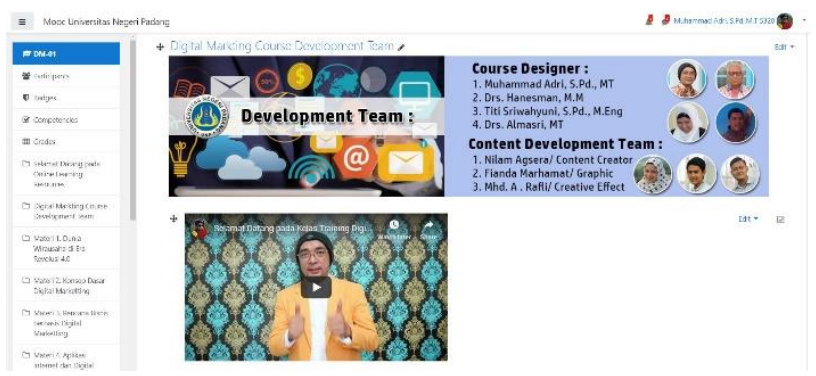

Gambar 8. Halaman Pengantar DMLR

4. Hasil Implementasi

DMLR berbasis LMS yang telah dirancang dan dikembangkan, kemudian diimplementasikan sebagai pendukung Pembelajaran dan Pembinaan DM bagi mahasiswa di UNP. Untuk menguji implementasi DMLR ini, ujicoba dilakukan dengan partisipan 30 mahasiswa DM dengan akun masing-masing, dengan masa ujicoba selama 1 bulan, bersamaan dengan program pendampingan peserta.

Dari hasil ujicoba ini diperoleh data berikut : 
Tabel 4. Hasil Ujicoba DMLR

\begin{tabular}{lllll}
\hline Aspek Belajar DM & SS & S & KS & TS \\
\hline $\begin{array}{l}\text { DMLR Membantu Mhs } \\
\text { dalam memahami DM }\end{array}$ & 27 & 3 & 0 & 0 \\
$\begin{array}{l}\text { Struktur Materi sesuai } \\
\text { dengan Kurikulum DM }\end{array}$ & 20 & 7 & 3 & 0 \\
Media Video Menarik & 26 & 3 & 1 & 0 \\
Tutorial Mudah difahami & 12 & 13 & 3 & 2 \\
Bahasa sederhana dan lugas & 17 & 10 & 2 & 1 \\
\hline
\end{tabular}

SS = Sangat Setuju, S = Setuju, KS = Kurang

Setuju, TS $=$ Tidak Setuju

5. Hasil Evaluasi

Setelah kegiatan pengembangan DMLR berbasis LMS selesai selanjutkan dilakukan evaluasi. Jumlah peserta yang dievaluasi berjumlah 30 mahasiswa DM. Evaluasi pertama yang dilakukan adalah peningkatan ketermpilan TIK, seperti terlihat pada Tabel 5.

Tabel 5. Data pemetaan kompetensi DM Mahasiswa

\begin{tabular}{lllll}
\hline Kompetensi TIK Dasar & PM & MN & MH & JML \\
\hline Pengoperasian Komputer & 6 & 14 & 10 & 30 \\
Aplikasi Office & 5 & 14 & 9 & 30 \\
Aplikasi Desain Grafis & 8 & 15 & 7 & 30 \\
Aplikasi Video Editing & 8 & 16 & 6 & 30 \\
Akses Internet & 4 & 14 & 12 & 30 \\
Internet Resources & 8 & 14 & 8 & 30 \\
Social Network \& Media & 6 & 16 & 8 & 30 \\
Business on Digital & 10 & 14 & 6 & 30
\end{tabular}

Technology

$\mathrm{PM}=$ Pemula, $\mathrm{MN}=$ Menengah, $\mathrm{MH}=$ Mahir

Pada Tabel 5 dapat dilihat, terdapat peningkatan jumlah kompetensi mahasiswa pada level menengah dan mahir pada hamper semua bidang kompetensi dasar TIK, saat dibandingkan dengan data pada Tabel 5.

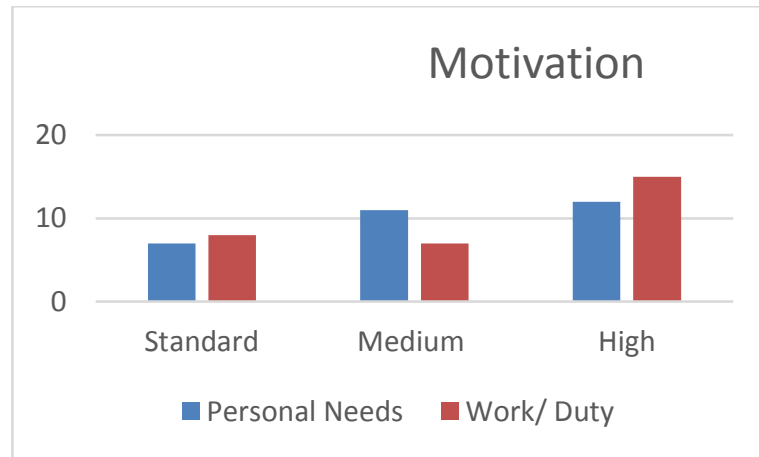

Gambar 9. Perbandingan dalam motivasi pribadi dan kerja sebagai mahasiswa dalam menggunakan TIK

Jika dilihat dari framework Digital Skill, pada aspek motivasi diperoleh data seperti terlihat pada Gambar 9 di atas, yang memperlihatkan, kecedrungan penggunaan perangkat untuk mendukung tugasnya sebagai mahasiswa.

Kemudian jika dilihat dari aspek material access, mayoritas mahasiswa menggunakan smartphone sebagai alat koneksi internet dan data.

\section{Material Access}

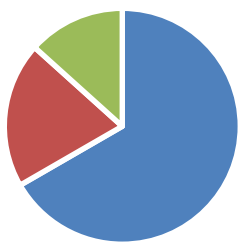

- Smartphone Wi-Fi on Campus a Private Wi-Fi

Gambar 10. Pemanfaatan Material Akes oleh mahasiswa DM

\section{Skill Access}

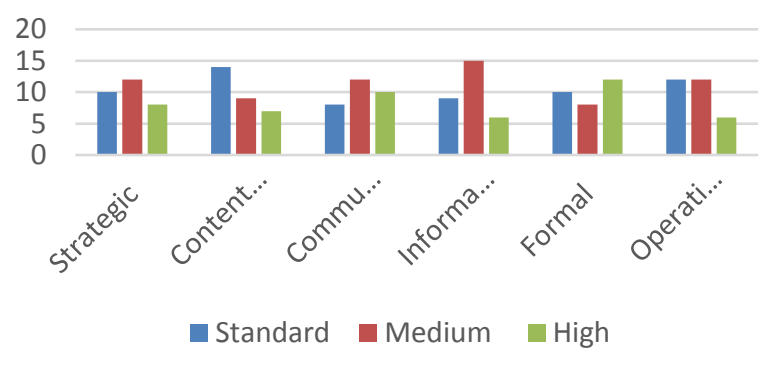

Gambar 11. Skill akses

Pada aspek skill akses ini, dapat dilihat terdapat beberapa kemampuan mahasiswa yang harus dibina agar dapat lebih memaksimalkan pemanfaatan TIK dalam DM.

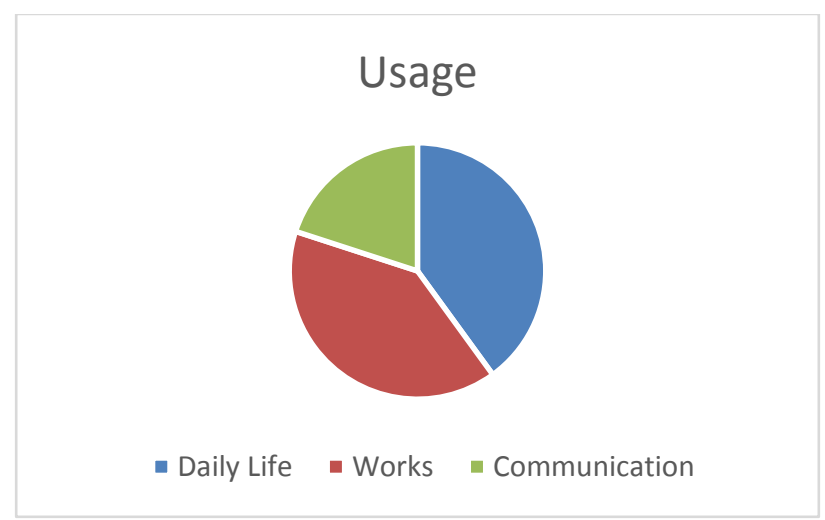

Gambar 12. Penggunaan TIK

Dari aspek penggunakan skill digital/ TIK, maka keterampilan tersebut berimbang 
dalam kebutuhan kehidupan sehari-hari dan tugas sebagai mahasiswa.

Berdasarkan hasil analisis dan data yang dperoleh selama pengembangan DMLR berbasis LMS dapat dilihat kesiapan mahasiswa dalam mengimplementasikan DM, bahwa Semua peserta memperoleh keterampilan TIK dengan peningkatan yang signifikan seperti yang terlihat dalam perbandingan Tabel 4 dan Tabel 5. Dari aspek motivasi, dapat dilihat bahwa peserta DM yang menggunakan TIK didorong oleh kebutuhan pribadi dan tuntutan tugas mahasiswa yang tinggi. Dari aspek akses material, sebagian besar peserta menggunakan perangkat pribadi seperti smartphone sebagai alat dalam mengakses TIK. Pada aspek keterampilan akses TIK, maka pada level strategi akses pada level medium, pembuatan konten pada level standar, kemampuan komunikasi dan informasi pada level medium, sedangkan pada akses formal pada level tinggi dan operasional medium. Dalam hal penggunaan, ada keseimbangan antara pribadi dan pekerjaan

\section{KESIMPULAN}

Hasil penelitian dan pembahasan tentang pengembangan BL Digital Marketing berbasis LMS sebagaimana yang telah diuraikan diatas, yang memperlihatkan beberapa kecenderungan yang dapat disimpulkan sebgai berikut:

1. Semua peserta memiliki ketertarikan dan kesiapan dalam DM yang tinggi

2. Dari analisis dengan Digital Skill Framework, dapat dilihat bahwa semua responden memiliki kesiapan yang baik dalam mengimplementasikan model bisinis berbasis $\mathrm{DM}$

3. DM telah meningkatkan semangat berwirausaha mahasiswa di UNP secara signifikan.

\section{DAFTAR PUSTAKA}

[1] Rojko, Andreja, "Industry 4.0 : Concept and Background". International Journal of Interactive Mobile Technology, vol. 11, no.5, pp. 77-90, 2017.

[2] Bogovitz, Aleksei V, et.al, "Comparative Analysis of Formation of Industry 4.0 in Developed and Developing Countries", E. G. Popkova et al. (eds.), Industry 4.0: Industrial Revolution of the 21st Century, Studies in Systems, Decision and Control 169, pp. $155-$ 164, Springer International Publishing AG, part of Springer Nature 2019, https://doi.org/10.1007/978-3-319-94310-

7_15

[3] Fox, Armando, "Using MOOC to Reinvigorate Software Engineering Education", on ICSE Companion, ACM, 31th May - 7th June, 2014, Hyderabad, India.

[4] Hawkins, B.D. 2015. Here comes generation Z: What makes them tick? Neatoday.org. Website http://neatoday.org/2015/07/13/here-comesgeneration-z-what-makes-them-thick. diakses tanggal 5 Juni 2019

[5] Montrieux H, Vanderlinde R, Schellens T, De Marez L, "Teaching and Learning with Mobile Technology: A Qualitative Explorative Study about the Introduction of Tablet Devices in Secondary Education". PLoS ONE 10 (12) : e0144008. https://doi.org/10.1371/journal.pone.0144008

[6] Muhammad Ruslan, Pendidikan di Era RI 4.0 dan Tantangannya, 2019. Website: https://www.kompasiana.com/2220/5aebb94e ab12ae687e7f5153/pendidikan-di-era-ri-4-0dan-tantangannya?page $=$ all, diakses tanggal 5 Juni 2019.

[7] Soekartono, evolusi 4.0 dan Dampaknya terhadap Pendidikan di Indonesia, 2018. http://fkip.ums.ac.id/wpcontent/uploads/sites/43/2018/12/RevolusiIndustri-4.0-dan-Dampaknya-terhadapPendidikan-di-Indonesia-Dr.-Sukartono.doc, diakses tanggal 5 Juni 2019

[8] Yulizar Kasih, "Mewujudkan Pendidikan Kewirausahaan Di Perguruan Tinggi Melalui Proses Pembelajaran yang Berkelanjutan", Forum Bisnis dan Kewirausahaan, Jurnal Ilmiah STIE MDP, Vol. 2 No. 2 Maret 2013

[9] Heri Kuswara. "Strategi Perguruan Tinggi Mewujudkan Entrepreneurial Campus", diakses pada alamat : http://www.dikti.go.id, diakses pada 10 April 2019.

[10] Elfindri, Desri Ayunda, dan Wiko Saputra, "Minang Entrepreneurship", Buduose Media, Jakarta, 2010.

[11] Rauch, E., Linder, C., \& Dallasega, P. "Anthropocentric perspective of production before and within Industry 4.0". Computers and Industrial Engineering, (xxxx), 1-15. https://doi.org/10.1016/j.cie.2019.01.018, 2010

[12] Yeung, S., "Examining the need of ethics course in China hospitality industry". Procedia - Social and Behavioral Sciences, 144, 212217, 2014. https://doi.org/10.1016/j.sbspro.2014.07.289 
[13] UNP Padang. Rencana Strategis Universitas Negeri Padang 2015-2019, UNP, Padang, 2016.

[14] UNP Padang, Laporan Kinerja Universitas Negeri Padang Tahun 2018, UNP, Padang, 2019.

[15] UPT MKU UNP. Rencana Pembelajaran Semester (RPS) Mata Kuliah Umum Kewirausahaan Universitas Negeri Padang, UPT. MKU UNP Padang, 2019.

[16] Harjanto Probowo, Blunder Paradigma menghadapi Era Industri 4.0, 2018 Website : https://onlinelearning.binus.ac.id/2018/08/02/ blunder-paradigma-menghadapi-era-industri4-0/, diakses tanggal 5 Juni 2019.

[17] Molenda, Michael. In Search of Eclusive ADDIE Model, Published on http://www.ispi.org, May/June 2003.

[18] Branch, Robert M, Instructional Design : The ADDIE Approach, Springer, New York, USA, 2009.

[19] Van Dijk, Jan A. G. M. and van Deuresen, Alexander, Digital Skill, unlocking the Information Society, New Palgrave MacMillan, York, USA, 2014

[20] Udemy, The Complete Digital Marketing Course, Website

https://www.udemy.com/course/learn-digitalmarketing-course/, diakses pada 5 Agustus 2019

[21] Udacity, Sylabus Digital Marketing Non Degree Program, Website : http://www.udacity.com/digital-marketing, diaksea pada 24 Agustus 2019

[22] Ondigitalmarketing.Sylabus for Digital Marketing Analytics, Website : https://ondigitalmarketing.com/learn/coursesyllabus-for-digital-marketing-analytics/, diakses pada 17 Oktober 2019.

[23] Google Trends, survey dari penggunaan LMS Moodle, Schoology, Dokeos, dan Atutor pada Google Trends 12 bulan terakhir, Website : Google. 2019. (https://trends.google.com) diakses pada tanggal 03 Agustus 2019.

[24] Moodle. 2019. Course Management with Moodle Guide, website : https://moodle.org, diakses tanggal 03 Agustus 2019.

[25] Rice, William, Moodle ELearning Course Development, 3rd Edition: A complete guide to create and develop engaging elearning courses with Moodle, Packt Publishing, Birmingham, UK, 2015. 